\title{
Paradox of Success-Mediated Conflicts: Analysing Attitudes of Local Communities Towards Successfully Reintroduced Tigers in India
}

\author{
Manjari Malviya, Sankar Kalyanasundaram and Ramesh Krishnamurthy* \\ Department of Landscape Level Planning and Management, Wildlife Institute of India, Dehradun, India
}

\section{OPEN ACCESS}

Edited by:

Adriana Consorte-McCrea,

Canterbury Christ Church University,

United Kingdom

Reviewed by:

Meena Venkataraman,

Carnivore Conservation and Research

(CCR), India

Bahar Baviskar,

Society for Wildlife Conservation,

Education and Research, India

*Correspondence:

Ramesh Krishnamurthy

ramesh@wii.gov.in

Specialty section: This article was submitted to

Animal Conservation,

a section of the journal

Frontiers in Conservation Science

Received: 26 September 2021 Accepted: 20 December 2021

Published: 21 January 2022

Citation:

Malviya M, Kalyanasundaram S and Krishnamurthy R (2022) Paradox of

Success-Mediated Conflicts:

Analysing Attitudes of Local Communities Towards Successfully

Reintroduced Tigers in India.

Front. Conserv. Sci. 2:783467.

doi: 10.3389/fcosc.2021.783467
Conservation programs such as reintroductions are pivotal for the survival and proliferation of endangered species like tigers. However, restoring a carnivore population may create unforeseen problems for communities by fuelling human-wildlife conflict. The long-term persistence of tigers can only be ensured when the support of these local communities is garnered for conservation efforts, especially in release sites from where they were initially eliminated due to anthropogenic causes. The first step to gaining support for tigers and their reintroduction programs is to understand how local communities perceive these large carnivores. This study thus assessed the attitudes of local communities towards the reintroduced tigers of India, in the Panna and Sariska Tiger Reserves, and examined the socio-economic factors that potentially shape their attitudes. Questionnaire surveys were conducted in 330 households across 25 villages in Panna, and 361 households across 32 villages in Sariska. Decision tree and multinomial logistic regression analyses were employed to identify the explanatory variables associated with attitudes. In Panna, more respondents (52.12\%) expressed negative opinions about tigers, as compared to positive (24.55\%). Whereas in Sariska, more respondents had positive opinions (47.92\%) than negative (34.90\%). In both the sites, the most frequent reason given by the respondents for their negative attitude towards tigers was "fear." Regression modelling suggests that gender and education are key factors associated with the attitude of local communities towards reintroduced tigers. Other factors, specific to the reserves, were the age of the respondent, age of lost livestock, compensation received, and value of fodder obtained from the reserve. Community engagement must be integrated into conservation projects with a focus on educating women and the elderly about carnivores, protecting the traditional rights of local communities, and compensating for their losses.

Keywords: gender, education, human-tiger conflict, Panna, Sariska 


\section{INTRODUCTION}

In the 21st century, "reintroduction" is frequently used as a tool for large carnivore conservation (Hayward and Somers, 2009), however, the human dimensions of such conservation programs are often overlooked, even though most of these carnivores were exterminated by humans or anthropogenic activities in the first place (Hartman, 1995). Moreover, reintroduced and revived populations of carnivores frequently get into conflict with humans (Stahl et al., 2001; Bangs et al., 2005). Making local communities the primary bearers of the cost of conservation in form of not only livestock loss due to conflict but also livelihood loss due to suspension of their traditional forest rights in the release sites (Green et al., 2018).

In India, after the original tiger population in two important "tiger reserves" was lost to poaching, from Sariska Tiger Reserve in 2005 and from Panna Tiger Reserve in 2009 (Narain et al., 2005; Wildlife Institute of India, 2009), a high-level committee convened by the Government of India recommended the reintroduction of tigers from other neighbouring reserves (Narain et al., 2005). Following this, reintroduction programs were launched in both the reserves and have been largely successful, especially in Panna (Sankar et al., 2013; Sarkar et al., 2016). The communities residing within and around these tiger reserves are highly dependent on the reserves for their subsistence, including for grazing their livestock (Jain and Sajjad, 2016; Malviya et al., 2018). The resultant high overlap of habitat use by humans and tigers in these reserves often results in human-tiger conflict (Sekhar, 1998; Kolipaka et al., 2017). The first tiger reintroduced at Sariska became a victim of this conflict when it was poisoned by a few villagers as retaliation for livestock loss (Sankar et al., 2013). Even before the reintroduction, the loss of the original tiger population in Sariska was also linked to human-wildlife conflict. The Bawarias (a nomadic hunting tribe) were hired by villagers to protect their crops against raiding by wildlife, in turn, indulged in poaching tigers and were given protection by the villagers (Dutt, 2004; Narain et al., 2005). A few cases have also been reported wherein tigers were killed to retaliate against cattle losses by local communities and then their parts were traded to these nomadic tribes who then supplied them to national and international smugglers (Shankar, 2007; Sansar Chand v. State of Rajasthan, 2010). In Panna also, nomadic hunting tribes like the Pardhis and Bawarias were identified as the primary reason for the local extinction of tigers (Srivastava, 2010). Thus, the persistence of tigers in these reserves is closely linked to how local communities perceive them.

As recently observed in the Satkosia Tiger Reserve in India, failure to ensure the support of local communities in areas where tigers are being translocated jeopardises the entire reintroduction program (Vasudeva et al., 2021). Therefore, for tiger conservation to succeed, whether it be at the individual tiger reserve level, like the Sariska and Panna Tiger Reserves, or at the national or global levels, it is imperative to have the support of local communities. To garner local support for conservation, it is crucial to understand the attitude of local communities towards these large carnivores.
Tolerance is often defined as acceptance of loss caused by a wild species (Kansky et al., 2014). However, experiencing first-hand loss by wildlife is not the only reason for negative attitudes towards them; people who have never experienced loss also express negative attitudes towards wildlife (Marchini and MacDonald, 2018). Studies have related attitude and the resulting tolerance of people towards large carnivores to a myriad of reasons. The reasons vary from socio-economic factors like age, gender, education level, occupation, community, household wealth, dependence on livestock for livelihood, number of livestock owned, livestock loss due to depredation/magnitude of loss, change in traditional practises, and the severity of effect that loss has on livelihood (Marchini and Macdonald, 2012; Kansky et al., 2014, 2016; Gebresenbet et al., 2018; Margulies and Karanth, 2018), to psychosocial factors like traditional or religious beliefs, inherent/cultural value, social trust and norms, fear, risk perception, past experiences, and hazard acceptance/acceptance capacity (Carter et al., 2012; Marchini and Macdonald, 2012; Banerjee et al., 2013; Bruskotter and Wilson, 2014; Browne-Nuñez et al., 2015; Gebresenbet et al., 2018; Struebig et al., 2018). The protection status of carnivores, protected area management strategies, relationship or trust towards forest management/authorities or government agencies, and compensation to mitigate loss or other monetary incentives, also influences people's opinions about carnivores (Mishra et al., 2003; Karlsson and Sjöström, 2011; Banerjee et al., 2013; BrowneNuñez et al., 2015; Margulies and Karanth, 2018; Struebig et al., 2018). People are more accepting of problems caused by wild animals that they appreciate (Kaltenborn et al., 2006). Thus, their positive or negative opinions eventually dictate how tolerant people would be towards loss-causing wildlife, making it important to understand the attitudes people hold towards these large carnivores. Gaining an insight into the factors that determine these attitudes better equips us to design participatory tools to mitigate conflicts and accomplish lasting conservation goals.

Thus, through this study, we wanted to examine the attitude of local communities towards conflict causing large carnivores in sites where they have been reintroduced, and highlight the factors that explain these attitudes. Although qualitative studies have been conducted in Sariska and Panna to assess perceptions towards reintroduced tigers (Kolipaka et al., 2015; Doubleday, 2018), no quantitative study has been done in these reserves to identify the drivers of attitudes towards reintroduced tigers, which may help managers develop effective strategies to ameliorate attitudes and engage communities in tiger conservation. Therefore, we have modelled various socio-economic factors against the attitudes of people towards reintroduced tigers in the Sariska and Panna Tiger Reserves and discussed the explanatory factors that may have far-reaching conservation implications.

\section{METHODS}

\section{Study Area}

Sariska Tiger Reserve $\left(27^{\circ} 5^{\prime} \mathrm{N}\right.$ to $27^{\circ} 33^{\prime} \mathrm{N}$ and $76^{\circ} 17^{\prime} \mathrm{E}$ to $\left.76^{\circ} 34^{\prime} \mathrm{E}\right)$ is situated in the Alwar district of the state of 


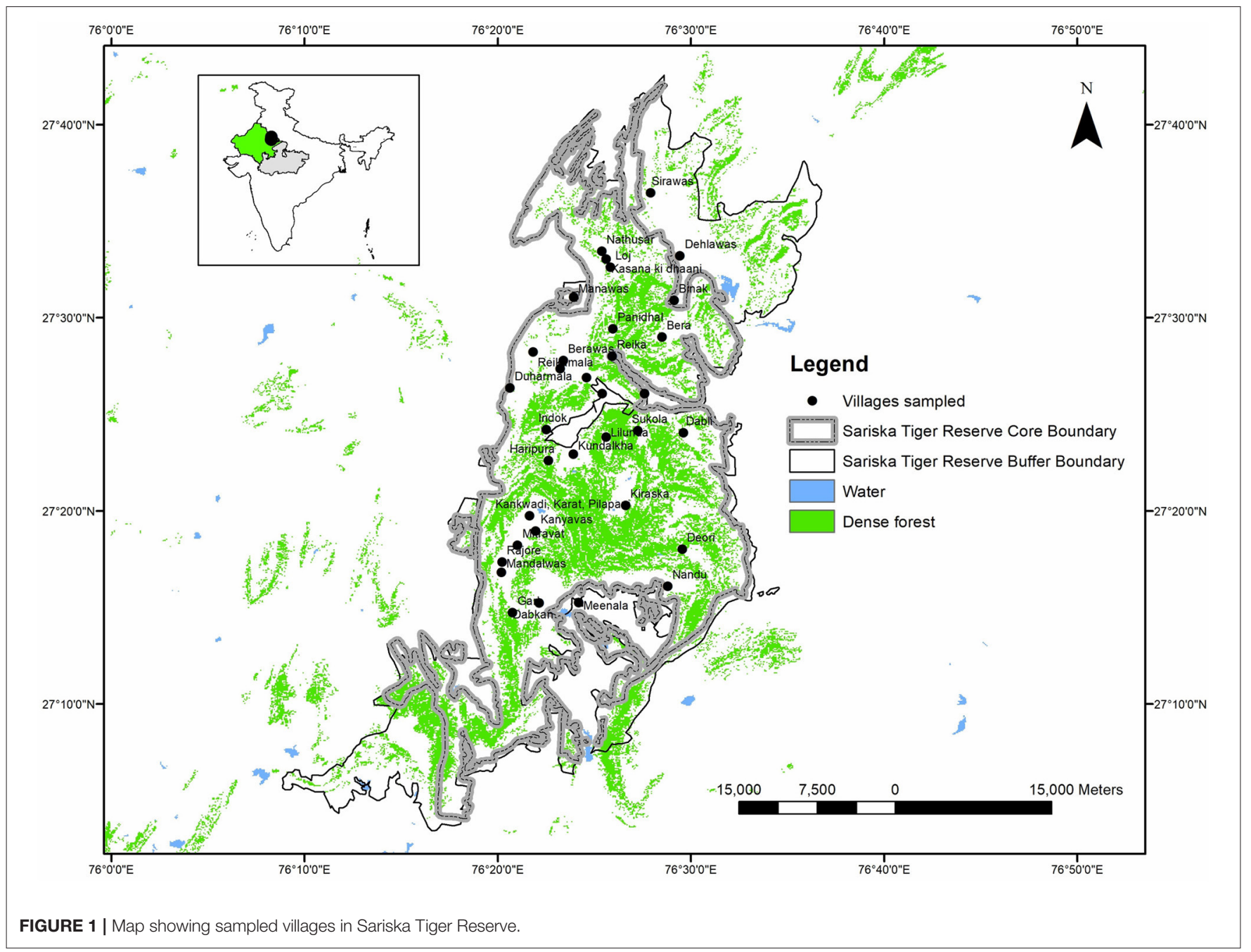

Rajasthan in western India (Figure 1). The Critical Tiger Habitat (CTH) of Sariska Tiger Reserve covers an area of $881 \mathrm{~km}^{2}$, of which $400.14 \mathrm{~km}^{2}$ has been preliminarily notified as a national park. The buffer of the reserve is $334 \mathrm{~km}^{2}$. There are 26 villages inside $\mathrm{CTH}$, nine of which are within the notified national park area. The buffer of the reserve has 146 villages. The entire reserve is exploited by the local communities for fuelwood and fodder, putting it under a lot of anthropogenic pressure (Malviya et al., 2018).

Panna Tiger Reserve $\left(24^{\circ} 27^{\prime} \mathrm{N}\right.$ to $24^{\circ} 46^{\prime} \mathrm{N}$ and $79^{\circ} 45^{\prime} \mathrm{E}$ to $80^{\circ} 9^{\prime} \mathrm{E}$ ) is situated in the Panna and Chhatarpur districts of the state of Madhya Pradesh in central India. The CTH or core of Panna Tiger Reserve is composed of Panna National Park and Gangau Wildlife Sanctuary covering an area of $576 \mathrm{~km}^{2}$, and the buffer covers an area of about $1,022 \mathrm{~km}^{2}$ (Figure 2). There are only four villages in the national park area and seven in Gangau Wildlife Sanctuary; hence, as compared to Sariska, there is large inviolate space available for tigers in the CTH (Malviya et al., 2018). However, 49 villages within the buffer of Panna Tiger Reserve are also dependent upon the fringes of the CTH.

\section{Survey Design}

Questionnaire surveys were carried out in selected villages within and around the reserves, in 2016-2017 (Oppenheim, 2000). Village list and locations were obtained from the forest department of both the reserves, along with livestock compensation data (2009-2015 for Panna and 2011-2016 for Sariska). In the case of Sariska, all 27 villages within the CTH were sampled; additionally, 20\% $(n=5)$ of the conflict-facing villages outside the $\mathrm{CTH}$ were randomly sampled (Supplementary Table 1). In Panna, all villages inside the national park area plus two villages on the national park boundary were sampled $(n=6)$. Additionally, villages within a $2 \mathrm{~km}$ buffer of the national park were stratified into high ( $>10$ cases of livestock loss), low (1-10 cases of livestock loss), and no conflict ( 0 cases of livestock loss) villages on the basis of compensation data, and then randomly sampled ( $n=$ 19) (Supplementary Table 2). Within villages, households were selected randomly.

Thus, a total of 361 households across 32 villages were sampled in Sariska and 330 households from 25 villages were sampled in Panna. The semi-structured questionnaire was aimed at 


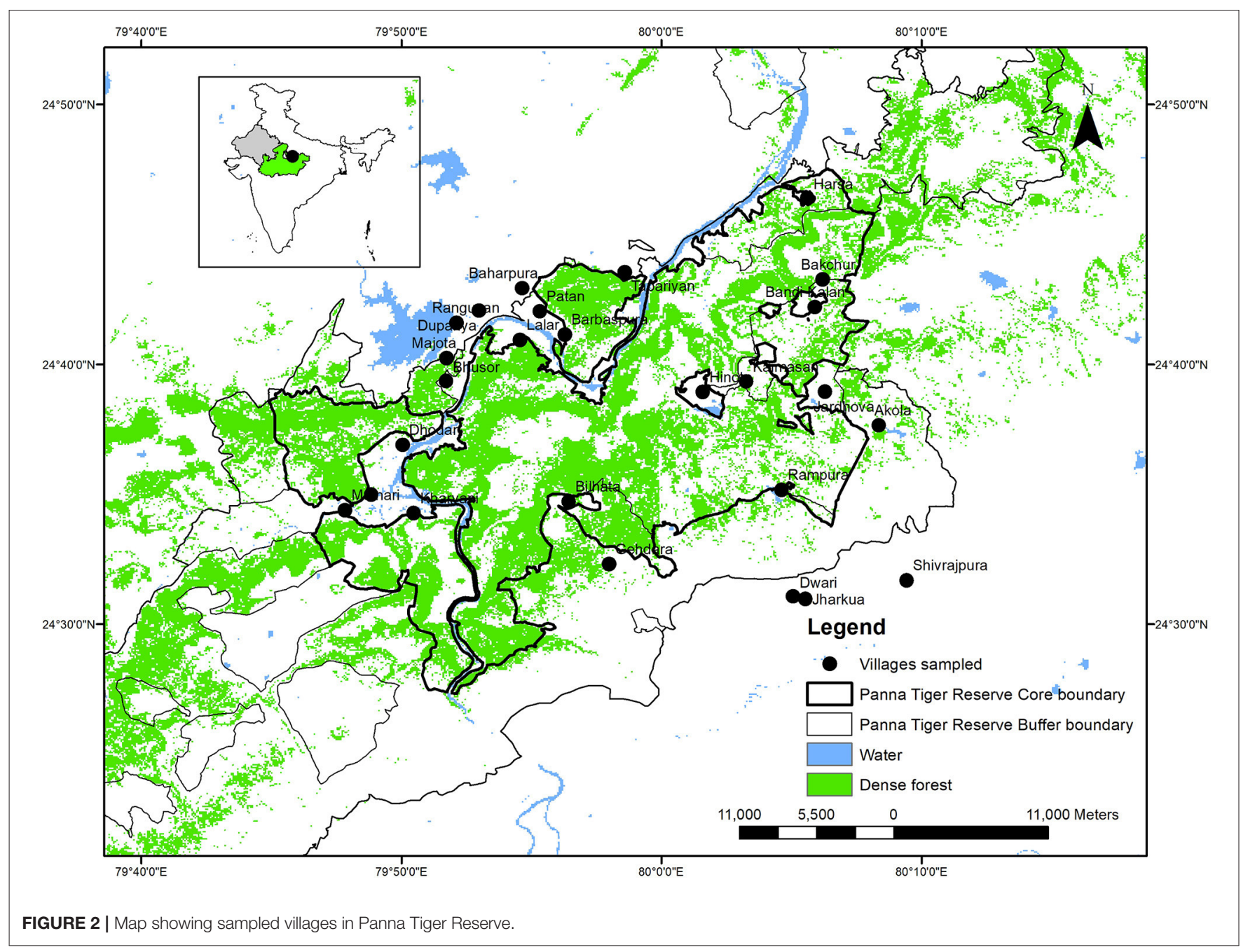

understanding demography, livelihood strategies and household economics, resource dependencies, livestock loss due to tigers, crop damage by herbivores, and, the attitude of people towards reintroduced tigers.

Respondents were asked about their opinion of reintroduced tigers. In case they could not comprehend the question, they were prompted whether they liked tigers or disliked them and why. Their answers were then dubbed as positive, negative, mixed, and neutral. "Negative" opinion meant people stated that they "dislike tiger" and/or made negative statements such as "tigers are a threat to their life and livelihood." While "positive" opinion meant people stated that they "like tigers" and/or expressed positive views, such as "tigers are beautiful" or "tigers should be present in the jungle." Others who made such statements as "tiger are beautiful, but they also inflict harm" were treated as "mixed." People who expressed no opinion about the tiger, citing that they "did not know anything about tiger" or "have never seen a tiger and never had to do anything with one," were dubbed as "neutral." The interviews were conducted by the first author, thus maintaining consistency and avoiding observer bias.

\section{Statistical Modelling}

To understand the factors that were shaping the attitudes of people towards reintroduced tigers, at the inception we employed decision tree analyses (Kohavi and Quinlan, 2002), to see how the variables were interacting and get an initial idea as to which variables might be important. Following which we employed multinomial logistic regression to identify the factors associated with attitudes (Böhning, 1992). This we did for both Sariska and Panna. Since we believed that the attitudes might be different for the general populace, and for those who have faced direct losses due to the species, we ran a separate analysis for all the sampled households and households having faced direct loss, within both reserves. The explanatory variables tested were village location (inside or outside the core of the reserve) of the respondent, respondent's age, sex, education level, community, economic status (household income), livestock holding, and livestock loss suffered due to tiger, last livestock species lost, and its age, compensation received, compensation satisfaction levels, the value of fodder obtained from reserve forest, profits from non-timber forest produce (NTFP) collection and crop loss due 
to wild herbivores. Analysis was done in the statistical package for the social sciences (SPSS) version 27 (IBM Corp., 2020).

For decision tree analyses, CRT (Classification and Regression Tree) was selected as the growing method, and model validation was done using the 10-fold cross-validation method (Borovicka et al., 2012). Stopping criteria were predefined, maximum tree depth was set at five and a minimum number of cases for parent and child nodes in the case of Sariska were set as 50 and 25, respectively (IBM Corp., 2020). For Panna, due to the smaller sample size when analysing all the cases, parent and child nodes were set as 30 and 15, respectively. Plus, since conflict-only data set was even smaller, parent and child nodes were set as 18 and 9 , respectively.

Since, attitudes were recorded as multiple categorical variables, i.e., positive, negative, mixed, and neutral, we employed multinomial logistic regression after checking for its assumptions i.e., linearity of independent variables and $\log$ odds, and multicollinearity (Peng et al., 2002; Stoltzfus, 2011; Park, 2013). Based on the correlation results, highly correlated variables were not used together in a model (Supplementary Table 3). Stepwise backward model selection was based on partial $p$-values and final model selection was based on pseudo $\mathrm{R}^{2}$ and discrimination ability (classification accuracy and area under the curve (AUC) value of the receiver operating characteristic (ROC) curve).

\section{RESULTS}

\section{Demography and Social System}

In Panna, of the 330 respondents, $68.79 \%$ were men and $31.21 \%$ were women. The average age of the respondents was $43.52 \pm 16.20$. Most (52.42\%) of the sampled household belonged to the other backward class (OBC) category, of which Yadavs (predominantly agro-pastoralists) comprised the largest proportion, followed by Scheduled Tribe (ST) category (32.12\%), dominated by Gonds (a forest-dwelling tribe). In Sariska, of the 361 respondents, $66.76 \%$ were men and $33.24 \%$ were women. The average age of the respondents was $41.80 \pm 16.04$ years. Gujjar (predominantly pastoralists), classified as $\mathrm{OBC}$, was the dominant community (62.33\%), followed by Meena (an agropastoralist tribe) (16.07\%) (classified as ST), and 15 others.

\section{Education}

Most of the respondents were illiterate, in both Panna (57.88\%) and Sariska (66.48\%). Illiteracy was higher among women in both the reserves, $75.73 \%$ and $86.66 \%$ of women were illiterate as compared to $50.66 \%$ and $56.43 \%$ of men, in Panna and Sariska, respectively.

\section{Livelihood, Forest Dependence, and Household Economics}

In Panna, most of the households were involved in agriculture (77.81\%), manual labour (54.41\%), selling NTFPs (42.25\%), and livestock husbandry $(36.78 \%)$, often in combination with each other. In total $66.06 \%(n=218)$ of the sampled households, owned livestock. Of these 218 households, $66.97 \%(n=146)$ depend upon the forest for fodder and graze their livestock in the tiger reserve. In Sariska, most of the households were involved in both livestock rearing and agriculture (52.63\%), followed by only livestock rearing (20.78\%), and, livestock rearing and agriculture plus manual labour $(6.09 \%)$. It was found that $97.5 \%(n=352)$ of all the sampled households owned livestock, $96 \%$ of which depend upon tiger reserve for fodder.

Based on the number of cattle owned and dependence upon the forest for fodder (partial or complete and total number of days for which they depend upon forest), the value/cost of fodder collected from reserve forest by each household was estimated, the average being INR 44,038 (USD 584.03) per year per household for Panna, and INR 2,75,757.5 (USD 3,657.09) per year per household for Sariska.

\section{Crop Loss due to Herbivores}

In Panna, 70\% $(n=231)$ of sampled households were reportedly facing crop loss due mostly to wild pig and nilgai, followed by chital, monkey, jackal, porcupine, hare, bear, civet, and chinkara, in that order. In Sariska, $67.6 \%(n=244)$ of sampled households were facing crop loss due to mostly wild pig and nilgai, followed by sambar, peafowl, monkey, porcupine, and hare, in that order.

\section{Human-Tiger Conflict and Compensation}

In Panna, of the 330 respondents, $27.27 \%(n=90)$ reported livestock loss by reintroduced tigers (between 2009 and 2016), of which $57.78 \%(n=52)$ applied for compensation; of these 59.62\% $(n=31)$ received compensation. In Sariska, 29.64\% $(n=$ 107) of sampled households reported loss by reintroduced tigers (between 2009 and 2017), of which 71.03\% $(n=76)$ applied for compensation; of these $53.95 \%(n=41)$ received compensation.

\section{Attitude of Local Communities Towards Tigers}

Among the 330 respondents we interviewed in Panna, 24.55\% ( $n$ $=81)$ had positive attitudes towards tigers, $52.12 \%(n=172)$ had negative attitudes, $2.12 \%(n=7)$ had mixed, $17.27 \%(n=$ 57) had neutral responses while $3.93 \%(n=13)$ said they "don't know." Irrespective of whether respondents perceived themselves to be facing a loss or not, they were more negative towards tigers $\left(\chi^{2}=0.202 ; p=0.653\right)$ (Table 1). Women gave more neutral responses as compared to men, while men gave more positive responses as compared to women (Table 2). In total 31 communities were sampled in Panna, of which 11 were more positive and 16 were more negative, notably, the two dominant communities of Gonds and Yadavs had more respondents with negative attitudes towards tigers, as compared to positive. Of

TABLE 1 | Attitude of interviewees that have faced livestock loss due to tiger, towards tiger, in Panna and Sariska Tiger Reserve.

\begin{tabular}{lccccc}
\hline \multirow{2}{*}{ Loss suffered } & \multicolumn{4}{c}{ Attitude } \\
\cline { 2 - 3 } & \multicolumn{2}{c}{ Panna Tiger Reserve } & & \multicolumn{2}{c}{ Sariska Tiger Reserve } \\
\cline { 2 - 3 } \cline { 5 - 6 } & $\begin{array}{c}\text { Positive } \\
\text { (\%) }\end{array}$ & $\begin{array}{c}\text { Negative } \\
\text { (\%) }\end{array}$ & & Positive & Negative \\
& 23 & 54 & & 44 & (\%) \\
\hline Yes & 25 & 51 & & 50 & 39 \\
No & & & & & 33
\end{tabular}


TABLE 2 | Gender-wise attitude of local communities towards tigers in Panna and Sariska Tiger Reserve.

\begin{tabular}{|c|c|c|c|c|}
\hline \multirow[t]{4}{*}{ Attitude } & \multicolumn{4}{|c|}{ Gender } \\
\hline & \multicolumn{2}{|c|}{ Panna Tiger Reserve } & \multicolumn{2}{|c|}{ Sariska Tiger Reserve } \\
\hline & Male (\%) & Female (\%) & Male (\%) & Female (\%) \\
\hline & $(N=227)$ & $(N=103)$ & $(N=241)$ & $(N=120)$ \\
\hline Like/positive & 28.19 & 16.50 & 60.17 & 23.33 \\
\hline Dislike/negative & 52.86 & 50.49 & 26.97 & 50.83 \\
\hline Can't tell/don't have any opinion/neutral & 13.22 & 26.21 & 8.30 & 21.67 \\
\hline Don't know & 2.64 & 6.80 & 1.24 & 2.50 \\
\hline
\end{tabular}

all the sampled respondents, only 105 were able to articulate specific reasons for why they liked or disliked tigers. The reason stated by people who had negative attitudes $(n=80)$ were, most frequently (35\%), fear for their life and livestock, closely followed by losses $(28.75 \%$ ) caused by tigers. Some respondents (15\%) expressed negative opinions about tigers because they had negative sentiments towards the forest department. At the same time, some respondents $(n=6)$ expressed a positive opinion of tigers because they were employed by the forest department.

Among the 361 respondents we interviewed in Sariska, 47.92\% $(n=173)$ had positive attitudes towards tigers, $34.90 \%$ ( $n$ $=126$ ) had negative attitudes, while four respondents gave mixed responses; $12.74 \%(n=46)$ gave neutral responses, while $1.66 \%(n=6)$ said they "don't know." Irrespective of whether respondents perceived to be facing loss or not, they were more positive towards tigers $(\chi 2=1.326 ; p=0.249)$ (Table 1). The attitudes of female respondents were more likely to be either neutral or negative as compared to men (Table 2). A total of 17 communities were sampled in Sariska, of which nine were more positive and seven were more negative, notably, the dominant communities of Gujjars and Meenas, had more respondents with positive attitudes towards tigers, as compared to negative. Among the respondents, only 40 were able to articulate the reasons for why they liked or disliked tigers. Respondents who expressed a positive opinion of tigers $(n=13)$ mostly $(38.46 \%)$ believed that "tigers are king/pride of jungle." The reason stated by people who had negative attitudes $(n=27)$ were, most frequently $(44.44 \%)$, fear for their life and livestock, and negative sentiments towards the forest department (29.63\%).

Our results show that the attitude of respondents varied significantly between the two study sites, with a significant difference between the number of respondents having a negative attitude towards tigers, as compared to positive, in Sariska and Panna $(\chi 2=36.85 ; p<0.001)$.

\section{Factors Associated With the Attitude of Local Communities Towards Tigers Panna Tiger Reserve \\ All Sampled Households}

Decision tree analyses revealed that education was the most important classifier but due to the small dataset the tree did not split any further. Close examination of the classification reveals that people who have received education higher than high school were more positive $(59.1 \%)$ while people who were less educated

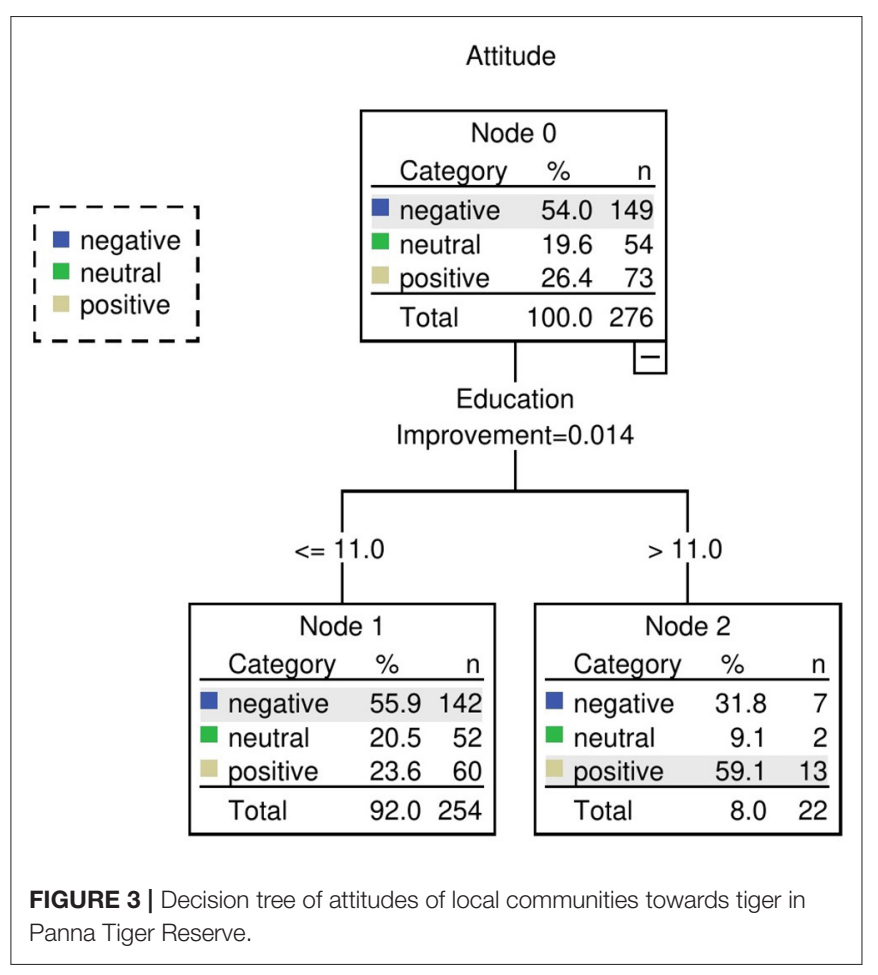

were more negative (55.9\%) (Figure 3). Overall classification accuracy of the model was $56.2 \%$ (Risk $=0.457$ ).

While constructing multinomial logistic regression models we considered the results of the decision tree and kept education as a key explanatory variable. The multinomial logistic regression model with seven predictor variables, viz. education $(p=0.019)$, total livestock ( $p=0.127)$, total household income $(p=0.369)$, total income from forest products $(p=0.533)$, gender $(p=$ $0.006)$, village location $(p=0.276)$, and crop loss due to wild herbivores $(p=0.414)$, was selected $(p=0.001)$. The Nagelkerke R-square indicated that $17.2 \%$ of the total variations in attitudes occurred due to the variations among the seven predictor variables. The classification accuracy of the model was $53.71 \%$. The AUC of the ROC curve for the model was 0.62 (positive actual state as negative opinion), which means the model has class separation capacity.

Attitude towards tiger was influenced by gender and education of the respondent (Table 3). An overall neutral opinion 
TABLE 3 | Multinomial logistic regression model explaining the attitude of people towards tiger in Panna Tiger Reserve: parameter estimates.

\begin{tabular}{|c|c|c|c|c|c|c|c|}
\hline Attitude $^{a}$ & Parameters & B & Std. Error & Wald & df & $p$-value & $\operatorname{Exp}(B)$ \\
\hline \multirow[t]{11}{*}{ Neutral } & Intercept & -0.101 & 0.704 & 0.021 & 1 & 0.886 & \\
\hline & Education & -0.056 & 0.046 & 1.467 & 1 & 0.226 & 0.946 \\
\hline & Total livestock & 0.013 & 0.047 & 0.071 & 1 & 0.790 & 1.013 \\
\hline & Household income & -0.100 & 0.157 & 0.404 & 1 & 0.525 & 0.905 \\
\hline & Income FP & 0.000 & 0.000 & 0.004 & 1 & 0.949 & 1.000 \\
\hline & Gender $=\mathrm{M}$ & 1.161 & 0.411 & 7.968 & 1 & 0.005 & 3.194 \\
\hline & Gender = F & $0^{b}$ & 0.0 & 0.0 & 0 & 0.0 & 0.0 \\
\hline & Village $=$ in & 0.759 & 0.496 & 2.340 & 1 & 0.126 & 2.135 \\
\hline & Village $=$ out & $0^{b}$ & 0.0 & 0.0 & 0 & 0.0 & 0.0 \\
\hline & Crop loss $=0$ & -0.700 & 0.436 & 2.581 & 1 & 0.108 & 0.496 \\
\hline & Crop loss $=1$ & $0^{b}$ & 0.0 & 0.0 & 0 & 0.0 & 0.0 \\
\hline \multirow[t]{11}{*}{ Negative } & Intercept & 1.411 & 0.556 & 6.429 & 1 & 0.011 & \\
\hline & Education & -0.079 & 0.036 & 4.739 & 1 & 0.029 & 0.924 \\
\hline & Total livestock & 0.065 & 0.036 & 3.272 & 1 & 0.070 & 1.067 \\
\hline & Household income & -0.218 & 0.126 & 3.008 & 1 & 0.083 & 0.804 \\
\hline & Income FP & 0.000 & 0.000 & 0.556 & 1 & 0.456 & 1.000 \\
\hline & Gender $=\mathrm{M}$ & 0.438 & 0.353 & 1.539 & 1 & 0.215 & 1.550 \\
\hline & Gender $=\mathrm{F}$ & $\mathrm{O}^{\mathrm{b}}$ & 0.0 & 0.0 & 0 & 0.0 & 0.0 \\
\hline & Village = in & 0.720 & 0.402 & 3.196 & 1 & 0.074 & 2.053 \\
\hline & Village $=$ out & $0^{b}$ & 0.0 & 0.0 & 0 & 0.0 & 0.0 \\
\hline & Crop loss $=0$ & -0.412 & 0.332 & 1.544 & 1 & 0.214 & 0.662 \\
\hline & Crop loss $=1$ & $0^{\mathrm{b}}$ & 0.0 & 0.0 & 0 & 0.0 & 0.0 \\
\hline
\end{tabular}

a The reference category is: positive.

${ }^{b}$ This parameter is set to zero because it is redundant.

is influenced by the gender of the respondent, with odds of women expressing a neutral opinion rather than a positive one being 3.19 times higher than that of men $(p=0.005)$ (Table 3$)$. For the logistic regression model of negative opinion vs. positive, the odds of a more educated person to have a negative opinion rather than a positive one are 0.92 times than those of a less educated person $(p=0.029)$, meaning education is inversely related to negative opinion (Table 3 ).

\section{Household Facing Loss}

Decision tree analyses revealed that community was the most important classifier. Close examination of the classification reveals that respondents who were Brahman, Serare, and Mehtar were more positive $(66.7 \%)$ than negative $(0 \%)$, while all the other communities such as Gonds, Yadavs, etc., were more negative (61.4\%) than positive (25\%) (Figure 4). Overall classification accuracy of the model was $62.3 \%$ (Risk $=0.5$ ).

Even though the decision tree suggested that community was an important explanatory variable, it was not possible to use community as an explanatory variable in the multinomial model due to high SE associated (as a result of a large number of communities and a small dataset). Thus, the multinomial model with seven predictor variables, viz. value of fodder obtained from forest $(p=0.034)$, age $(p=0.032)$, total livestock owned ( $p$ $=0.071)$, total livestock lost $(p=0.007)$, age of last livestock lost $(p=0.023)$, species of last livestock lost $(p=0.061)$, and compensation received $(p=0.020)$, was selected $(p=0.003)$. The
Nagelkerke R-square was $47.5 \%$. The classification accuracy of the model was $72.46 \%$. The AUC of the ROC curve for the model was 0.54 (positive actual state as negative opinion). Attitudes towards tigers among households facing direct loss were influenced by age of the respondent, age of the last livestock lost to a tiger, and compensation received (Table 4). The odds for older respondents to have a negative opinion rather than a positive one is 1.074 times higher than a younger person $(p=0.034)$, i.e., older people are more likely to have negative opinions about tigers. The odds for respondents that have received compensation to have a negative opinion rather than a positive one is 0.21 times than a respondent that has not received compensation $(p=0.042)$, meaning people who have received compensation are less likely to have a negative opinion towards tigers (and more likely to have a positive opinion), as compared to a person who has not received compensation. The odds for respondents losing mature cattle to a tiger having a negative opinion rather than a positive one is, 91.52 times higher than a respondent losing immature cattle ( $p=$ $0.015)$, i.e., people losing mature productive cattle are much more likely to have negative opinions about tigers (Table 4).

\section{Sariska Tiger Reserve All Sampled Households}

Decision tree analyses revealed that sex (gender) was the most important classifier, followed by cost (value) of fodder obtained from the forest. Close examination of the splits reveals that female respondents were more negative $(54.5 \%)$ than positive $(22.2 \%)$ 


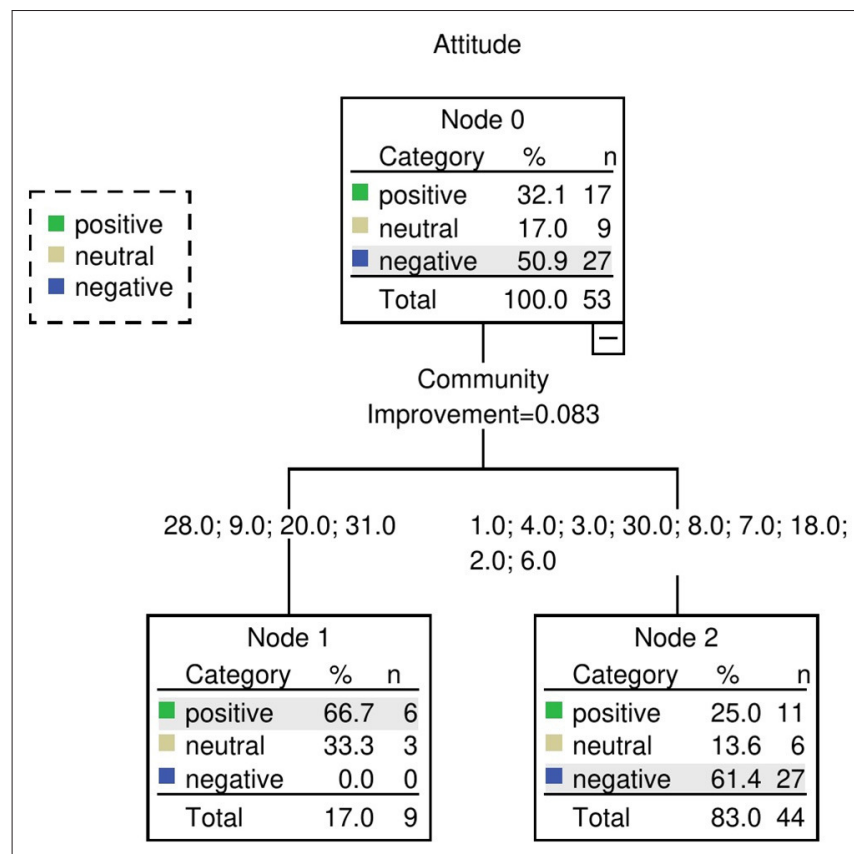

FIGURE 4 | Decision tree of attitudes of households that have faced livestock loss due to tiger in Panna Tiger Reserve. or neutral (23.2\%) while male respondents were more positive $(63.5 \%)$ than negative $(27.4 \%)$ or neutral $(9.1 \%)$. The next split reveals that women who are drawing greater benefits from the reserve in form of a higher value of fodder obtained from the forest were more positive as compared to women who obtained less fodder from the forest, even though women were more negative in general (Figure 5). Overall classification accuracy of the model was $60.6 \%$ (Risk $=0.39$ ).

While constructing multinomial logistic regression models we considered the results of the decision tree and kept gender and value of fodder obtained from the forest as a key explanatory variable. The multinomial logistic regression model with three predictor variables, viz. education $(p=0.024)$, gender $(p<$ 0.001 ), and value of fodder obtained from the forest $(p=$ 0.028 ), was selected $(p<0.001)$. The Nagelkerke R-square was $22.2 \%$. The classification accuracy of the model was $60 \%$. The AUC of the ROC curve for the model was 0.69 (positive actual state as positive opinion). Attitude towards tigers among local communities was influenced by the gender and education of the respondent, as well as the value of the fodder collected from the forest (Table 5).

Neutral opinion is influenced by the education of the respondent, with odds of a more educated person expressing a neutral opinion rather than a positive one being 0.86 times than a less educated person $(p=0.011)$. The odds of women expressing a neutral opinion rather than a positive one are 5.07 times higher than those of men $(p<0.001)$ (Table 5). The odds of respondents that collect more fodder from the reserve forest expressing a neutral opinion rather than a positive one are 0.99 times higher than respondents that collect less fodder $(p=0.010)$.
For the logistic regression model of negative opinion vs. positive, the odds of women having a negative opinion rather than positive are 4.93 times higher than men $(p<0.001)$ (Table 5).

\section{Household Facing Loss}

Decision tree analyses again revealed that sex (gender) was the most important classifier. Female respondents were more negative $(52.9 \%)$ than positive $(23.5 \%)$ or neutral $(23.5 \%)$ while male respondents were more positive $(60.4 \%)$ than negative $(30.2 \%)$ or neutral (9.4\%) (Figure 6). Overall classification accuracy of the model was $57.5 \%$ (Risk $=0.471$ ).

While constructing multinomial logistic regression models we considered the results of the decision tree and kept gender as a key explanatory variable. The multinomial logistic regression model with three predictor variables, viz. gender $(p=0.005)$, species of last livestock lost $(p=0.108)$, and value of fodder obtained from forest $(p=0.169)$, was selected $(p=0.003)$. The Nagelkerke R-square was $23.9 \%$. The classification accuracy of the model was $62.07 \%$. The AUC of the ROC curve for the model was 0.61 (positive actual state as positive opinion).

Attitude towards tigers among households facing direct loss is influenced by the gender of the respondent, with odds of women expressing a neutral opinion rather than a positive one being 6.01 times than those of men $(p=0.012)$ and a negative opinion rather than a positive one being 4.23 times than those of men $(p=0.007)$ (Table 6).

\section{DISCUSSION}

Retaliatory killing is driving large carnivore populations to extinction in many countries (Inskip and Zimmermann, 2009). However, killing a large carnivore is not only retaliatory in nature but driven by multiple psychosocial factors (Bruskotter and Wilson, 2014; Inskip et al., 2014). Sometimes it is not socioeconomic status or the intensity of loss but the negative attitude stemming from general beliefs towards the carnivores that makes them vulnerable to being killed by people (Carter et al., 2012; Inskip et al., 2014). Attitude is, thus, the most important predictor of the acceptance of large carnivores like tigers by local communities, with a general attitude towards tigers along with other sociopsychological factors translating to tiger killing and its societal acceptance (Inskip et al., 2014).

Both Sariska and Panna present a unique case in the form of being the only two tiger populations in India that were reintroduced back into a habitat from which they were poached out of existence recently, with local communities likely playing a part in the initial extinction (Narain et al., 2005). Thus, we expected the attitudes towards reintroduced tigers to be largely negative in both these reserves. However, we found that in Sariska, more respondents had positive opinions towards tigers, as compared to negative. Although in Panna, the trend was inverse, with more respondents expressing negative opinions towards tigers as compared to positive.

It is to be noted that an earlier study done in Panna by Kolipaka et al. (2015) found that people are tolerant 
TABLE 4 | Multinomial logistic regression model explaining the attitude of people facing loss, towards tiger in Panna Tiger Reserve: parameter estimates.

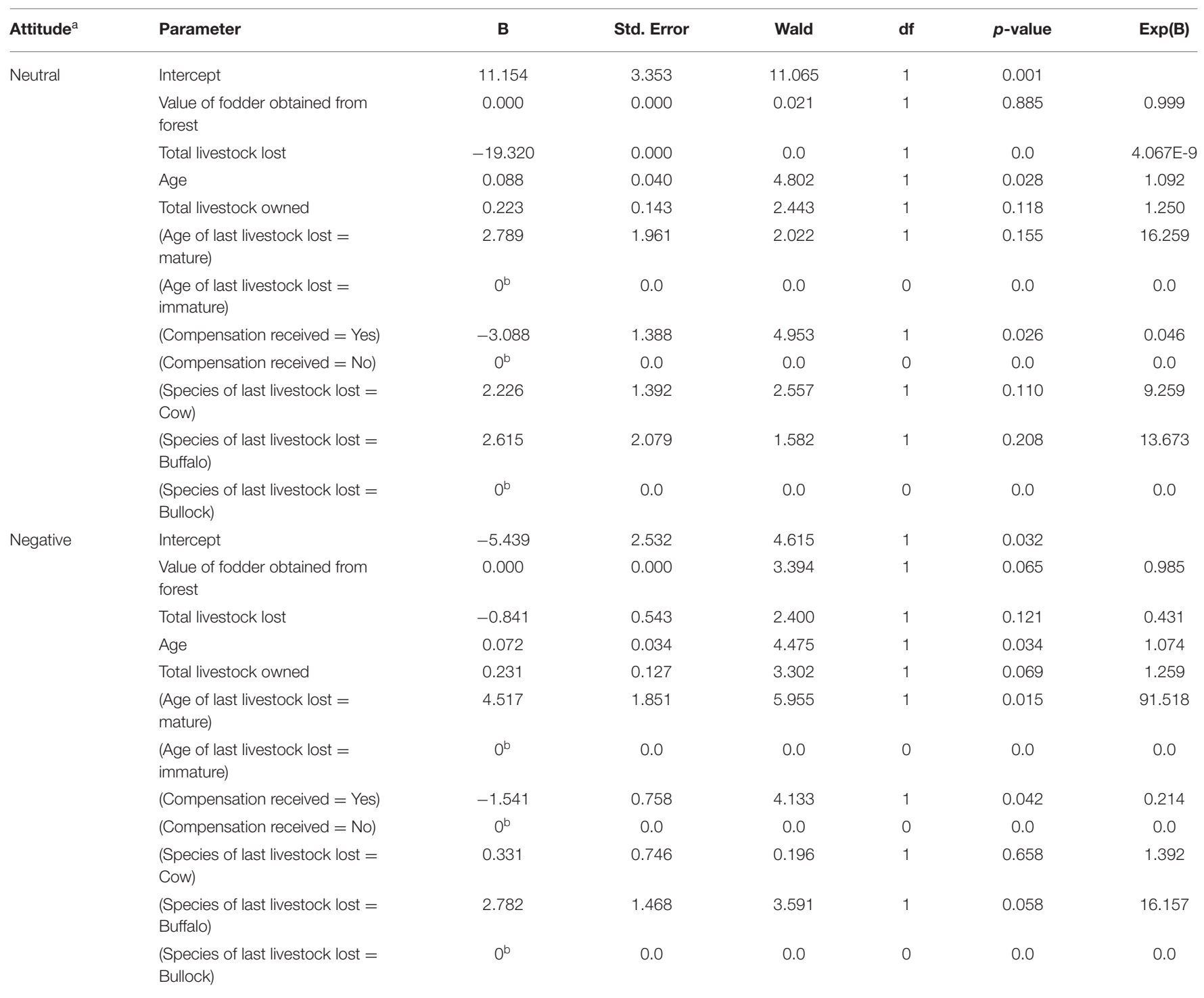

a The reference category is: positive.

${ }^{b}$ This parameter is set to zero because it is redundant.

of tigers in the area. It could be because as Kolipaka et al. (2015) also observed, the tiger presence was limited in the buffer area (in 2014), and livestock killing by tigers was occurring only in a few pockets, affecting only a few pastoralists. However, the range of the tigers has since increased, thus increasing the chances of people encountering tigers, which potentially increased the number of people that feel threatened.

In both Panna and Sariska, irrespective of whether the households were facing loss or not, the proportions of positive and negative attitudes were the same, indicating that direct cost does not explain attitudes towards reintroduced tigers in India (Inskip et al., 2016; Kansky et al., 2016). Loss faced by households was also not selected as the explanatory variable for the attitudes of people in our modelling. Therefore, merely reducing livestock loss may not automatically bring about change in the attitude of the people. Social, cultural, and environmental factors are likely to play a bigger role in determining the attitude of people as compared to economic loss (Struebig et al., 2018). Thus, unravelling these factors will be crucial in managing conservation attitudes. It was found that attitudes towards reintroduced tigers in India were guided by the gender and education level of the respondents. "Fear for life and livestock" and "conflict with reserve management" were the most oft-stated reason by the respondents expressing negative opinions towards tigers. Apart from these common factors, there were site-specific factors that were also explaining the attitude of people towards tigers in the two reserves. In the successive paragraphs we shall first discuss the factors common across populations, and then briefly discuss site-specific factors. 


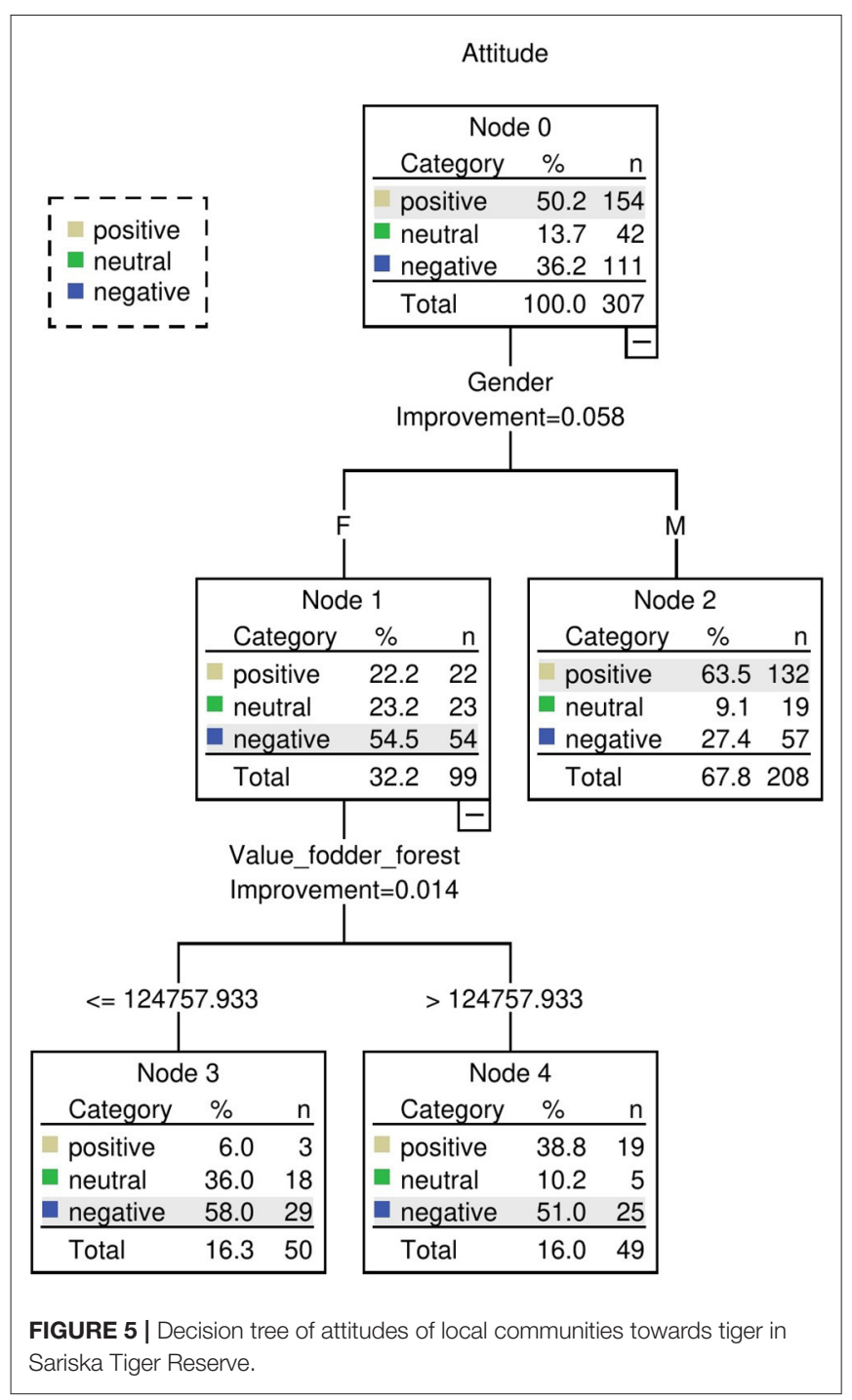

We have also attempted to explicate how these factors are likely intertwined.

\section{Major Factors Gender}

In both Sariska (23\%) and Panna (17\%) very few women expressed positive opinion towards tigers as compared to men, which resonates with earlier studies that not only does gender influence attitudes towards wildlife, women are more negative towards large carnivores as compared to men (Kaltenborn et al., 2006; Mir et al., 2015; Marchini and MacDonald, 2018; Karanth et al., 2019; Meena et al., 2021). An earlier study undertaken in Sariska also found that women had negative perceptions of tigers (Doubleday and Adams, 2020). It could be because men and women perceive risk differently (Gore and Kahler, 2012). It could be a construct of their different social roles, trust in authorities, and even how empowered they feel (Ogra, 2008; Gore and Kahler, 2012). Women bear a disproportionate burden of conflict costs but are often not included in decision-making processes, much less in conservation-related discussions, and hence might more readily express negative opinions (Ogra, 2008; Doubleday and Adams, 2020).

\section{Education}

Women in rural India also have fewer opportunities to gain formal education as compared to men, and thus are not exposed to the modern idea of conservation. In both Sariska and Panna, more women were uneducated as compared to men. It is known that education plays a crucial role in shaping attitudes towards wildlife, with educated people being more positive (Gebresenbet et al., 2018; Karanth et al., 2019). Education has been found to have a bearing on an individual's acceptance of carnivores and the success of conservation programs, more educated people being more pro-conservation (Hazzah, 2007; Karlsson and Sjöström, 2011; Pinheiro et al., 2016). In both Sariska and Panna, it was found that the more educated a person, the less likely they were to express negative opinions of tigers.

\section{Fear}

The major reason for disliking tigers as given by respondents in our study, in both Panna and Sariska, was 'fear' for their life and livestock. Many studies have found that women are more negative or less tolerant than men towards "fear" inducing concerning species such as large carnivores or megaherbivores (Gadd, 2005). This was found to be even more so in forestdwelling communities, as in the case of Sariska and Panna, where women are the ones going into the forest for water or the collection of forest produce and hence are more vulnerable (Gadd, 2005; Ogra, 2008; Rubino and Doubleday, 2021). Thus, negative attitudes towards predators, especially in the case of women, often stem from fear of the species (Kaltenborn et al., 2006; Marchini and Macdonald, 2012). Furthermore, a recent study done in Sariska has shown that this fear towards tigers is augmented by the vulnerable position of women in the patriarchal Indian household (Doubleday and Adams, 2020).

\section{Relationship With Reserve Management}

Negative interactions of local communities with forest management that may have aggressive conservation strategies can also result in a decline of tolerance for wildlife (Bond and Mkutu, 2018; Margulies and Karanth, 2018). In fact, behind much human-wildlife conflict is human-human conflict (Bond and Mkutu, 2018) seated in class divides and public-government standoffs (Skogen and Krange, 2003). In Panna, people expressed negative sentiments towards the forest department, and because they termed tigers as "their (the forest department's) tigers," and by extension of association people did not like the tigers as well. They felt that in the olden days, they would be compensated for losses caused due to wildlife by collecting profitable NTFPs, but now citing the protected status of these forests, they have been incapacitated to do so by the forest department. Thus, feeling less empowered makes them feel more frustrated over their present circumstances. It has led to a buildup of negative sentiments towards the forest department. Although forest department-supported eco-development committees have been active in these forests, providing people with gas connections 
TABLE 5 | Multinomial logistic regression model explaining the attitude of people towards tiger in Sariska Tiger Reserve: parameter estimates.

\begin{tabular}{|c|c|c|c|c|c|c|c|}
\hline Attitude $^{a}$ & Parameters & B & Std. Error & Wald & df & $p$-value & $\operatorname{Exp}(B)$ \\
\hline \multirow[t]{5}{*}{ Neutral } & Intercept & -0.938 & 0.342 & 7.531 & 1 & 0.006 & \\
\hline & Education & -0.003 & 0.001 & 6.573 & 1 & 0.010 & 0.997 \\
\hline & Fodder from forest & -0.153 & 0.061 & 6.401 & 1 & 0.011 & 0.858 \\
\hline & Gender $=\mathrm{F}$ & 1.624 & 0.404 & 16.174 & 1 & 0.000 & 5.072 \\
\hline & Gender $=\mathrm{M}$ & $0^{b}$ & 0.0 & 0.0 & 0 & 0.0 & 0.0 \\
\hline \multirow[t]{5}{*}{ Negative } & Intercept & -0.430 & 0.249 & 2.997 & 1 & 0.083 & \\
\hline & Education & -0.001 & 0.001 & 2.310 & 1 & 0.129 & 0.999 \\
\hline & Fodder from forest & -0.052 & 0.032 & 2.685 & 1 & 0.101 & 0.949 \\
\hline & Gender $=\mathrm{F}$ & 1.595 & 0.309 & 26.713 & 1 & 0.000 & 4.930 \\
\hline & Gender $=\mathrm{M}$ & $\mathrm{O}^{\mathrm{b}}$ & 0.0 & 0.0 & 0 & 0.0 & 0.0 \\
\hline
\end{tabular}

a The reference category is: positive.

${ }^{b}$ This parameter is set to zero because it is redundant.

and employment, most people are disengaged from these committees, not aware of their activities, and distrusting of the department. The distrust at both Panna and Sariska has been fuelled by inadequate relocation attempts (Shahabuddin et al., 2007). Traditional forest dwellers find it difficult to relocate outside of forest reserves and resent conservation programs or forest departments/governments that ask them to relocate, and the resultant negative sentiment spills over to the very species that the program seeks to conserve (Hazzah, 2007).

\section{Site-Specific Factors \\ Panna Tiger Reserve \\ Age}

Older people are more negative towards large carnivores as compared to younger people (Zimmermann et al., 2005; Kretser et al., 2009; Blekesaune and Rønningen, 2010; Cavalcanti et al., 2010; Marchini and Macdonald, 2012), with younger people being more pro-conservation (Arjunan et al., 2006; Hazzah, 2007; Karlsson and Sjöström, 2011; Consorte-McCrea et al., 2017; Meena et al., 2021). Similar results were obtained from Panna, where among the respondents that have faced direct loss due to tigers, older people were more likely to have negative opinions as compared to positive or neutral opinions, than younger people.

\section{Community}

The beliefs of an individual about right and wrong are shaped by the society they live in. It has been found that societal factors influence tolerance, perception, and eventually poaching of large carnivores more than the sentiment of an individual regarding retaliation or threat to life (Treves and Bruskotter, 2014). So, the community to which a person belongs shapes their opinion towards loss-causing wildlife (Kretser et al., 2009). Certain communities in Panna, owing to their high resource dependency on the reserve forest (such as the Yadavs), have also suffered higher losses due to tigers, and hence harbour more negative sentiments towards tigers.

\section{Age of Last Livestock Lost}

People who lost mature and more costly cattle were more likely to be negative towards tigers as compared to people who lost immature and less costly cattle. Indicating that among the people facing direct losses due to tigers, those experiencing higher economic loss may become more intolerant towards them (Rocha and Fortes, 2015).

\section{Compensation Received}

In Panna, households that have faced loss and were compensated for it were more positive towards tigers than households that have faced loss and not been compensated. Compensating people for their losses can significantly decrease their killing of carnivores (Hazzah et al., 2014). It has been observed that when local communities are benefitted by the presence of large carnivores either in the form of tourism benefits or compensation for loss, coupled with benefits from the forest in the form of free fodder (Naughton-Treves et al., 2003; Hazzah, 2007; Banerjee et al., 2013) people are more tolerant and in favour of conservation.

\section{Sariska Tiger Reserve}

\section{Forest Dependence and Community Beliefs}

Sometimes communities have been found to be highly tolerant of a large carnivore, even in face of high loss, because of their inherent values and the financial capability to bear the losses (Zimmermann et al., 2005). Unlike Panna, people in Sariska do not sell NTFP, but by depending on forest for fodder, they make considerable savings. This dependence of people on fodder plays a critical role in shaping their opinions. It has been observed that forest dwellers that enjoy grazing rights inside protected areas are more likely to coexist with large carnivores (Banerjee et al., 2013). In Sariska, local communities make a huge profit from selling milk products, the economics of which are sustained by free fodder and fuelwood from reserve forest, therefore, people who were drawing more benefit from the forest were also more positive towards the tigers. Moreover, in Sariska tigers are an important part of their legends and faith, and the people in general are very religious. In cultures across the world, tolerance towards carnivores is linked to their cultural and religious beliefs (Meena et al., 2021) because of which they see some carnivores as beneficial (Baynes-Rock, 2013) or revere them (Banerjee et al., 2013) even in the face of HWC (Can and Macdonald, 2018). In several cases, tolerance stemming from culture and beliefs has 


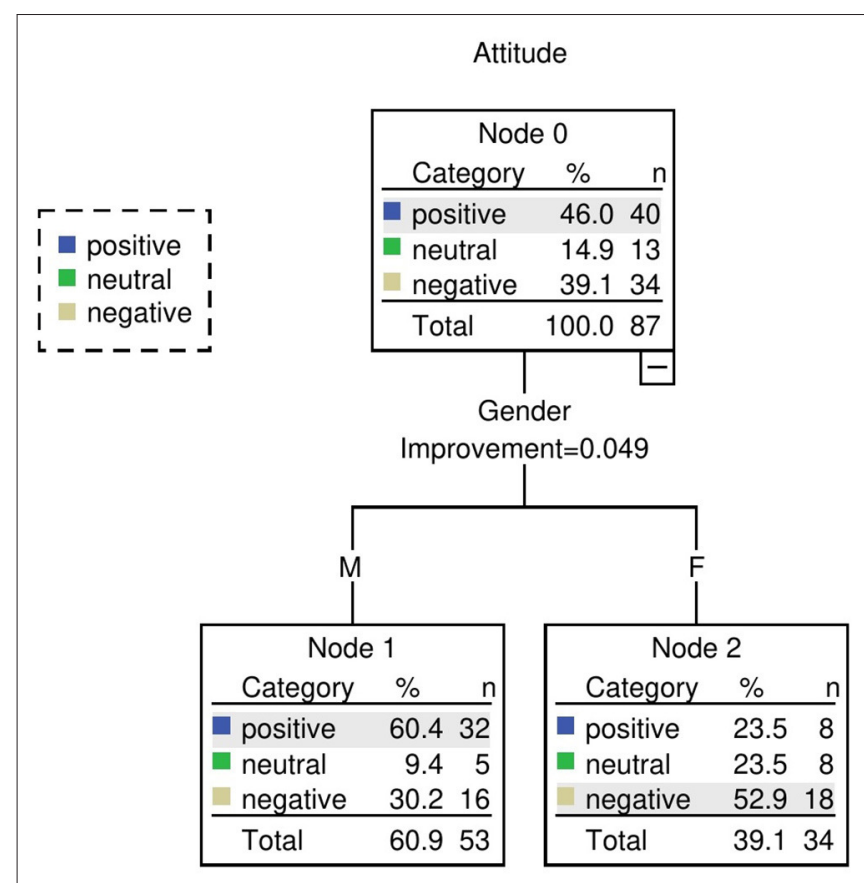

FIGURE 6 | Decision tree of attitudes of households that have faced livestock loss due to tiger in Sariska Tiger Reserve.

led to the long-term coexistence of carnivores such as Ethiopian hyenas and Gir lions with human beings (Banerjee et al., 2013; Baynes-Rock, 2013). Religion helps rural uneducated people rationalise risk (Inskip et al., 2016), thereby increasing the coping capacity of people towards loss-causing wildlife (Gogoi, 2018).

\section{Tourism}

Some people in Sariska were also positive towards tigers because they are involved in tourism activities as either vehicle owners, drivers, or guides. Eco-tourism is advocated to counter the losses faced by communities due to wildlife, because it incentivizes them for living in close proximity to wildlife, hence reducing negative attitudes (Hemson et al., 2009). However, in Sariska, even though some were being benefited by tiger safaris, benefits were largely limited to only two villages out of the 28 residing within the CTH. As also highlighted by other studies, communities often perceive tourism to be profitable for "government" and not them, because the profits from tourism are shared by very few in the community (Hemson et al., 2009).

\section{Recommended Strategies for Management of Attitudes Cost and Benefit}

Contrary to what might be expected, allowing people to eliminate conflict-causing carnivores does not change their attitude towards the carnivore or improve tolerance (BrowneNuñez et al., 2015). However, reducing tangible costs through compensation and increasing tangible benefits through ecotourism might be a good strategy (Kansky et al., 2016). People should be compensated for their losses immediately and the compensation process needs to be simplified. In the case of Sariska, benefits from tourism have been found to be correlated with support for the reserve in the past (Sekhar, 2003). Benefits incurred by tiger tourism should be spread out by encouraging local stakeholders over outsiders, in both of the reserves. At the same time letting forest-dwelling communities retain grazing or NTFP collection rights may be crucial in fashioning attitudes towards reserve management and wildlife. In Sariska, respondents who were getting more benefits from the forest were more positive towards tigers. This is because people make substantial profits from their dairy business, such that a few losses incurred by tigers may not make them negative. However, if they are not allowed to graze in the forest, and that in turn affects their capability to keep large livestock holdings, resulting in less profit, then the same number of livestock lost to tigers may invoke negative emotions.

Monetary incentives, therefore, are effective in the immediate alleviation of negative attitudes. However, incentives may work better if they are paired with social norms and educating people about the risk and benefit of the carnivore as well as, improving relationship with reserve management (de Pinho et al., 2014; Harvey et al., 2017).

\section{Education and Gender}

Since the level of education and knowledge about species influence attitudes towards wildlife (Pinheiro et al., 2016; Karanth et al., 2019; Meena et al., 2021), when people are educated about the benefits of the species, they become more tolerant (Bruskotter and Wilson, 2014). Poor knowledge about the species itself can lead to people attributing their loss to carnivores (Marchini and MacDonald, 2018). Thus, educating people about carnivores may decrease their sense of loss. Moreover, when people have correct knowledge about a carnivore, they also fear them less (Marchini and Macdonald, 2012) and will respond appropriately to conflict situations. Therefore, educating people can make them more positive towards carnivores, especially women, by allaying their fears and encouraging conservation values.

Receiving formal education and especially higher education inclines individuals towards conserving the environment (GEM Report, 2015). In both our study areas where formal education levels are low, and there are no regular programs for spreading awareness about conservation among the local communities; a multi-pronged approach is required, which firstly, focuses on ensuring formal education for both children, as well as, adults, especially women. Secondly, conducting conservation education and awareness programs, to reach the masses not covered by formal education. Lastly, sharing indigenous knowledge to promote traditional conservation values [Global Education Monitoring (GEM) Report Team, 2016]. Conservation education programs that take advantage of traditional beliefs and highlight the benefits of carnivores in a manner that is relatable to the target communities may make people more accepting of large carnivores and pro-conservation (Carter et al., 2012; Gebresenbet et al., 2018). Studies have suggested involving religious leaders in places where attitudes towards carnivores are guided by religious sentiment (Hazzah, 2007). Therefore, roping in local religious leaders for promoting tiger conservation may make attitudes 
TABLE 6 | Multinomial logistic regression model explaining the attitude of people facing loss towards tiger in Sariska Tiger Reserve: Parameter estimates.

\begin{tabular}{|c|c|c|c|c|c|c|c|}
\hline Attitude $^{a}$ & Parameters & B & Std. Error & Wald & df & $p$-value & $\operatorname{Exp}(B)$ \\
\hline \multirow[t]{6}{*}{ Neutral } & Intercept & -1.324 & 0.884 & 2.243 & 1 & 0.134 & \\
\hline & $\begin{array}{l}\text { Value of fodder obtained } \\
\text { from forest }\end{array}$ & 0.000 & 0.000 & 2.786 & 1 & 0.095 & 1.000 \\
\hline & (Gender = F) & 1.793 & 0.711 & 6.354 & 1 & 0.012 & 6.010 \\
\hline & (Gender = M) & $0^{\mathrm{b}}$ & 0.0 & 0.0 & 0 & 0.0 & 0.0 \\
\hline & $\begin{array}{l}\text { (Species of last livestock } \\
\text { lost = Buffalo) }\end{array}$ & 0.298 & 0.792 & 0.141 & 1 & 0.707 & 1.347 \\
\hline & $\begin{array}{l}\text { (Species of last livestock } \\
\text { lost }=\text { Cow) }\end{array}$ & $0^{\mathrm{b}}$ & 0.0 & 0.0 & 0 & 0.0 & 0.0 \\
\hline \multirow[t]{6}{*}{ Negative } & Intercept & 0.024 & 0.550 & 0.002 & 1 & 0.965 & \\
\hline & $\begin{array}{l}\text { Value of fodder obtained } \\
\text { from forest }\end{array}$ & 0.000 & 0.000 & 0.210 & 1 & 0.647 & 1.000 \\
\hline & (Gender = F) & 1.442 & 0.535 & 7.274 & 1 & 0.007 & 4.228 \\
\hline & (Gender = M) & $0^{b}$ & 0.0 & 0.0 & 0 & 0.0 & 0.0 \\
\hline & $\begin{array}{l}\text { (Species of last livestock } \\
\text { lost = Buffalo) }\end{array}$ & -0.898 & 0.519 & 2.991 & 1 & 0.084 & 0.407 \\
\hline & $\begin{array}{l}\text { (Species of last livestock } \\
\text { lost }=\text { Cow) }\end{array}$ & $0^{\mathrm{b}}$ & 0.0 & 0.0 & 0 & 0.0 & 0.0 \\
\hline
\end{tabular}

a The reference category is: positive.

${ }^{b}$ This parameter is set to zero because it is redundant.

more positive in both of the reserves, especially in the case of the elderly, who might respond to religious values more than conservation ethics.

Women have responded very positively to environmental education in the past, which has resulted in them supporting the conservation of endangered species (WWF TAL Project, n.d.). They have further turned into educators themselves, teaching their children and larger community the conservation value of a species and even employing this knowledge for income generation (Hausheer and Waters, 2016). Arjunan et al. (2006) found that in the Kalakad-Mudanthurai Tiger Reserve in India, women were more positive towards the tiger and its conservation than men. The positive opinion was a result of an eco-development project that was benefiting women more than men were. Similar efforts can be made in Sariska and Panna, by strengthening eco-development committees and ensuring women's participation in them, so that women not only become aware of conservation issues but also become active participants in natural resource management decision-making at the household and village levels.

\section{Summary}

Understanding the attitude of people towards tigers and factors that help formulate these attitudes is critical to ensure the longterm persistence of tigers in India, especially in habitats where they have been reintroduced. We found gender and education to be important determinants of attitudes towards reintroduced tigers. Encouraging education, particularly that of rural women, should thus be aimed at, to ensure people's participation in the conservation of large carnivores. If people do not feel safe and secure, it creates challenges for the protection of large carnivores, especially in the human interface areas. The best way forward would be to ensure a shared vision and integrate both livelihood and conservation aspects into the governance and management actions. Consultation with local communities should thus be an integral part of the planning and implementation process for any conservation program. More so, in the case of costly conservation programs like translocation/reintroduction, which directly impact the lives and livelihoods of the forest-dwelling communities.

\section{DATA AVAILABILITY STATEMENT}

The raw data supporting the conclusions of this article will be made available by the authors, without undue reservation.

\section{ETHICS STATEMENT}

Ethical review and approval was not required for this study in accordance with the local legislation and institutional requirements.

\section{AUTHOR CONTRIBUTIONS}

Material preparation, data collection, and analysis were performed by MM. Funds for the study, and requisite approvals from the forest departments of Madhya Pradesh and Rajasthan, were obtained by RK and SK. The first draft of the manuscript was written by MM. All authors commented on previous versions of the manuscript, contributed to the study's conception and design, read and approved the final manuscript. 


\section{FUNDING}

This work was supported by National Tiger Conservation Authority (NTCA), India [NTCA Letter No1-3/93-PT(Vol.II) dated 05th March 2012] and Madhya Pradesh Forest Department, India [MPFD D.O No - 01 dated 03-01-2015].

\section{ACKNOWLEDGMENTS}

We are grateful to the National Tiger Conservation Authority (NTCA), the Government of India, and the State Forest Departments of Madhya Pradesh and Rajasthan for funding and providing requisite permissions. We thank the Dean,

\section{REFERENCES}

Arjunan, M., Holmes, C., Puyravaud, J. P., and Davidar, P. (2006). Do developmental initiatives influence local attitudes toward conservation? A case study from the Kalakad-Mundanthurai Tiger Reserve, India. J. Environ. Manage. 79, 188-197. doi: 10.1016/j.jenvman.2005.06.007

Banerjee, K., Jhala, Y. V., Chauhan, K. S., and Dave, C. V. (2013). Living with lions: the economics of coexistence in the Gir forests, India. PLOS ONE 8:e89708. doi: 10.1371/journal.pone.0049457

Bangs, E. E., Fontaine, J. A., Jimenez, M. D., Meier, T. J., Bradley, E. H., Niemeyer, C. C., et al. (2005). "Managing wolf-human conflict in the northwestern United States," in People and Wildlife: Conflict or Coexistence?, eds R. Woodroffe, S. Thirgood, and A. Rabinowitz (Cambridge: Cambridge University Press), 340-356. doi: 10.1017/CBO9780511614774.022

Baynes-Rock, M. (2013). Local tolerance of hyena attacks in East Hararge Region, Ethiopia. Anthrozoös 26, 421-433. doi: 10.2752/175303713X13697429464438

Blekesaune, A., and Rønningen, K. (2010). Bears and fears: cultural capital, geography and attitudes towards large carnivores in Norway. Norsk. Geogr. Tidsskr. 64, 185-198. doi: 10.1080/00291951.2010.528225

Böhning, D. (1992). Multinomial logistic regression algorithm. Ann. Inst. Stat. Math. 44, 197-200. doi: 10.1007/BF00048682

Bond, J., and Mkutu, K. (2018). Exploring the hidden costs of human-wildlife conflict in northern Kenya. Afr. Stud. Rev. 61, 33-54. doi: 10.1017/asr.2017.134

Borovicka, T., Jirina Jr, M., Kordik, P., and Jirina, M. (2012). "Selecting representative data sets," in Advances in Data Mining Knowledge Discovery and Applications, ed A. Karahoca (Rijecka: InTech), 43-70. doi: 10.5772/50787

Browne-Nuñez, C., Treves, A., MacFarland, D., Voyles, Z., and Turng, C. (2015). Tolerance of wolves in Wisconsin: a mixed-methods examination of policy effects on attitudes and behavioral inclinations. Biol. Conserv. 189, 59-71. doi: 10.1016/j.biocon.2014.12.016

Bruskotter, J. T., and Wilson, R. S. (2014). Determining where the wild things will be: using psychological theory to find tolerance for large carnivores. Conserv. Lett. 7, 158-165. doi: 10.1111/conl.12072

Can, Ö. E., and Macdonald, D. W. (2018). Looking under the bonnet of conservation conflicts: can neuroscience help? Biodivers. Conserv. 27, 2087-2091. doi: 10.1007/s10531-018-1514-1

Carter, N. H., Riley, S. J., and Liu, J. (2012). Utility of a psychological framework for carnivore conservation. Oryx 46, 525-535. doi: 10.1017/S0030605312 000245

Cavalcanti, S. C., Marchini, S., Zimmermann, A., Gese, E. M., and Macdonald, D. W. (2010). "Jaguars, livestock, and people in Brazil: realities and perceptions behind the conflict," in The Biology and Conservation of Wild Felids, eds D. Macdonald, and A. Loveridge (Oxford: Oxford University Press), 383-402.

Consorte-McCrea, A., Nigbur, D., and Bath, A. (2017). Implications of teenagers' attitudes toward manned wolf conservation in Brazil. Canid Biol. Conserv. 20, 16-24. Available online at: http://www.canids.org/CBC/20/attitudes_ toward_maned_wolf_conservation.pdf

de Pinho, J. R., Grilo, C., Boone, R. B., Galvin, K. A., and Snodgrass, J. G. (2014). Influence of aesthetic appreciation of wildlife species on attitudes towards their
Director and colleagues (Dr. P. Nigam, Dr. D. Mandal, Mr. D. Chatterjee, Ms. D. Gupta, and Mr. S. Dutta) at the Wildlife Institute of India and field staff (Mr. V. Gujjar and Mr. B. Gujjar at Sariska, and Mr. P. Yadav at Panna Tiger Reserve) for providing support and facilitating field data collection. We thank Mr. S. Goswami for providing valuable inputs in manuscript preparation.

\section{SUPPLEMENTARY MATERIAL}

The Supplementary Material for this article can be found online at: https://www.frontiersin.org/articles/10.3389/fcosc. 2021.783467/full\#supplementary-material conservation in Kenyan agropastoralist communities. PLOS ONE 9:e88842. doi: 10.1371/journal.pone.0088842

Doubleday, K. F. (2018). Rewilding Expectations: Human-Environmental Relations in Context of Apex Predator Reintroduction in Rajasthan, India (PhD thesis). University of Texas at Austin, Austin, Tx, United States.

Doubleday, K. F., and Adams, P. C. (2020). Women's risk and well-being at the intersection of dowry, patriarchy, and conservation: the gendering of human-wildlife conflict. Environ. Plan. E Nat. Space 3, 976-998. doi: $10.1177 / 2514848619875664$

Dutt, B. (2004). Livelihood strategies of a nomadic hunting community of Eastern Rajasthan. Nomadic Peoples 8, 260-273. doi: 10.3167/082279404780446078

Gadd, M. E. (2005). Conservation outside of parks: attitudes of local people in Laikipia, Kenya. Environ. Conserv. 32, 50-63. doi: 10.1017/S0376892905001918

Gebresenbet, F., Bauer, H., Vadjunec, J. M., and Pape,ş, M. (2018). Beyond the numbers: human attitudes and conflict with lions (Panthera leo) in and around Gambella National Park, Ethiopia. PLoS ONE 13:e0204320. doi: 10.1371/journal.pone.0204320

GEM Report (2015). Education increases awareness and concern for the environment. World Education Blog. Available online at: https:// gemreportunesco.wordpress.com/2015/12/08/education-increases-awarenessand-concern-for-the-environment/ (accessed June 9 2021).

Global Education Monitoring (GEM) Report Team (2016). Global Education Monitoring Report. Education for People and Planet: Creating Sustainable Futures for All. Paris: UNESCO.

Gogoi, M. (2018). Emotional coping among communities affected by wildlife-caused damage in north-east India: opportunities for building tolerance and improving conservation outcomes. Oryx 52, 214-219. doi: 10.1017/S0030605317001193

Gore, M. L., and Kahler, J. S. (2012). Gendered risk perceptions associated with human-wildlife conflict: implications for participatory conservation. PLoS ONE 7:e32901. doi: 10.1371/journal.pone.0032901

Green, J. M. H., Fisher, B., Green, R. E., Makero, J., Platts, P. J., Robert, N., et al. (2018). Local costs of conservation exceed those borne by the global majority. Glob. Ecol. Conserv. 14:e00385. doi: 10.1016/j.gecco.2018.e00385

Hartman, P. (1995). Resolving conflicts between endangered species and man: case study-the reintroduction of gray wolves to Yellowstone National Park and Central Idaho. Environs Envtl. L. and Pol'y J. 18:88.

Harvey, R. G., Briggs-Gonzalez, V., and Mazzotti, F. J. (2017). Conservation payments in a social context: determinants of tolerance and behavioural intentions towards wild cats in northern Belize. Oryx 51, 730-741. doi: $10.1017 /$ S0030605316000545

Hausheer, J. E., and Waters, T. (2016). Why Conservation Needs Women: Supporting Women's Networks for Community Conservation. Available online at: https://blog.nature.org/science/2016/06/22/why-conservation-needswomen-gender-sex-community-conservation (accessed April 16, 2019).

Hayward, M. W., and Somers, M. (2009). Reintroduction of Top-Order Predators. Oxford: Wiley-Blackwell. doi: 10.1002/9781444312034

Hazzah, L., Dolrenry, S., Naughton, L., Edwards, C. T., Mwebi, O., Kearney, F., et al. (2014). Efficacy of two lion conservation programs 
in Maasailand, Kenya. Conserv. Biol. 28, 851-860. doi: 10.1111/cobi. 12244

Hazzah, L. N. (2007). Living Among Lions (Panthera leo): coexistence or killing? Community attitudes towards conservation initiatives and the motivation behind lion killing in Kenyan Maasailand (Master of Science dissertation). University of Wisconsin-Madison, Madison, WI, United States.

Hemson, G., Maclennan, S., Mills, G., Johnson, P., and Macdonald, D. (2009). Community, lions, livestock and money: a spatial and social analysis of attitudes to wildlife and the conservation value of tourism in a human-carnivore conflict in Botswana. Biol. Conserv. 142, 2718-2725. doi: 10.1016/j.biocon.2009.06.024

IBM Corp. (2020). IBM SPSS Statistics for Windows, Version 27.0. Armonk, NY: IBM Corp.

Inskip, C., Carter, N., Riley, S., Roberts, T., and MacMillan, D. (2016). Toward human-carnivore coexistence: understanding tolerance for tigers in Bangladesh. PLoS ONE 11:e0145913. doi: 10.1371/journal.pone.0145913

Inskip, C., Fahad, Z., Tully, R., Roberts, T., and MacMillan, D. (2014). Understanding carnivore killing behaviour: exploring the motivations for tiger killing in the Sundarbans, Bangladesh. Biol. Conserv. 180, 42-50. doi: 10.1016/j.biocon.2014.09.028

Inskip, C., and Zimmermann, A. (2009). Human-felid conflict: a review of patterns and priorities worldwide. Oryx 43:18. doi: 10.1017/S003060530899030X

Jain, P., and Sajjad, H. (2016). Household dependency on forest resources in the Sariska Tiger Reserve (STR), India: implications for management. J. Sustain. Forest. 35, 60-74. doi: 10.1080/10549811.2015.1099108

Kaltenborn, B. R. P., Bjerke, T., and Nyahongo, J. (2006). Living with problem animals - self-reported fear of potentially dangerous species in the Serengeti Region, Tanzania. Hum. Dimens. Wildl. 11, 397-409. doi: 10.1080/10871200600984323

Kansky, R., Kidd, M., and Knight, A. T. (2014). Meta-analysis of attitudes toward damage-causing mammalian wildlife. Conserv. Biol. 28, 924-938. doi: $10.1111 /$ cobi. 12275

Kansky, R., Kidd, M., and Knight, A. T. (2016). A wildlife tolerance model and case study for understanding human wildlife conflicts. Biol. Conserv. 201, 137-145. doi: 10.1016/j.biocon.2016.07.002

Karanth, K. K., Jain, S., and Weinthal, E. (2019). Human-wildlife interactions and attitudes towards wildlife and wildlife reserves in Rajasthan, India. Oryx 53, 523-531. doi: 10.1017/S0030605317001028

Karlsson, J., and Sjöström, M. (2011). Subsidized fencing of livestock as a means of increasing tolerance for wolves. Ecol. Soc. 16, 16. doi: 10.5751/ES-03878-160116

Kohavi, R., and Quinlan, J. R. (2002). "Data mining tasks and methods: classification: decision-tree discovery," in Handbook of Data Mining and Knowledge Discovery. Oxford: Oxford University Press.

Kolipaka, S. S., Persoon, G. A., De Iongh, H. H., and Srivastava, D. P. (2015). The influence of people's practices and beliefs on conservation: a case study on human-carnivore relationships from the multiple use buffer zone of the Panna Tiger Reserve, India. J. Hum. Ecol. 52, 192-207. doi: 10.1080/09709274.2015.11906943

Kolipaka, S. S., Tamis, W. L. M., van't Zelfde, M., Persoon, G. A., and de Iongh, H. H. (2017). Wild versus domestic prey in the diet of reintroduced tigers (Panthera tigris) in the livestock-dominated multiple-use forests of Panna Tiger Reserve, India. PLoS ONE 12:e0174844. doi: 10.1371/journal.pone.0174844

Kretser, H. E., Curtis, P. D., Francis, J. D., Pendall, R. J., and Knuth, B. A. (2009). Factors affecting perceptions of human-wildlife interactions in residential areas of northern New York and implications for conservation. Hum. Dimens. Wildl. 14, 102-118. doi: 10.1080/10871200802695594

Malviya, M., Kumar, V., Mandal, D., Sarkar, M. S., Nigam, P., Gopal, R., et al. (2018). Correlates of physiological stress and habitat factors in reintroductionbased recovery of tiger (Panthera tigris) populations. Hystrix 29, 195-201. doi: 10.4404/hystrix-00063-2018

Marchini, S., and Macdonald, D. W. (2012). Predicting ranchers' intention to kill jaguars: case studies in Amazonia and Pantanal. Biol. Conserv. 147, 213-221. doi: 10.1016/j.biocon.2012.01.002

Marchini, S., and MacDonald, D. W. (2018). Mind over matter: perceptions behind the impact of jaguars on human livelihoods. Biol. Conserv. 224, 230-237. doi: 10.1016/j.biocon.2018.06.001

Margulies, J. D., and Karanth, K. K. (2018). The production of human-wildlife conflict: a political animal geography of encounter. Geoforum 95, 153-164. doi: 10.1016/j.geoforum.2018.06.011
Meena, V., Johnson, P. J., Zimmermann, A., Montgomery, R. A., and Macdonald, D. W. (2021). Evaluation of human attitudes and factors conducive to promoting human-lion coexistence in the Greater Gir landscape, India. Oryx 55, 589-598. doi: 10.1017/S0030605319000760

Mir, Z. R., Noor, A., Habib, B., and Veeraswami, G. G. (2015). Attitudes of local people toward wildlife conservation: a case study from the Kashmir Valley. Mt. Res. Dev. 35, 392-400. doi: 10.1659/MRD-JOURNAL-D-15-00030.1

Mishra, C., Allen, P., Maccarthy, T., Madhusudan, M. D., Bayarjargal, A., and Prins, H. H. T. (2003). The role of incentive programs in conserving the snow leopard. Conserv. Biol. 17, 1512-1520. doi: 10.1111/j.1523-1739.2003.00092.x

Narain, S., Singh, S., Panwar, H. S., and Gadgil, M. (2005). Joining the Dots: The Report of the Tiger Task Force. Project Tiger, Union Ministry of Environment and Forests, New Delhi. Available online at: https://projecttiger.nic.in/ WriteReadData/PublicationFile/full_report.pdf (accessed April 22, 2017).

Naughton-Treves, L., Grossberg, R., and Treves, A. (2003). Paying for tolerance: rural citizens' attitudes toward wolf depredation and compensation. Conserv. Biol. 17, 1500-1511. doi: 10.1111/j.1523-1739.2003.00060.x

Ogra, M. V. (2008). Human-wildlife conflict and gender in protected area borderlands: a case study of costs, perceptions, and vulnerabilities from Uttarakhand (Uttaranchal), India. Geoforum 39, 1408-1422. doi: 10.1016/j.geoforum.2007.12.004

Oppenheim, A. N. (2000). Questionnaire Design, Interviewing and Attitude Measurement. London: Continuum International Publishing Group.

Park, H. (2013). An introduction to logistic regression: from basic concepts to interpretation with particular attention to nursing domain. J. Korean Acad. Nurs. 43, 154-164. doi: 10.4040/jkan.2013.43.2.154

Peng, C. Y. J., Lee, K. L., and Ingersoll, G. M. (2002). An introduction to logistic regression analysis and reporting. J. Educ. Res. 96, 3-14. doi: 10.1080/00220670209598786

Pinheiro, L. T., Rodrigues, J. F. M., and Borges-Nojosa, D. M. (2016). Formal education, previous interaction and perception influence the attitudes of people toward the conservation of snakes in a large urban center of northeastern Brazil. J. Ethnobiol. Ethnomed. 12, 1-8. doi: 10.1186/s13002-016-0 096-9

Rocha, L. C., and Fortes, V. B. (2015). Perceptions and attitudes of rural residents towards capuchin monkeys, in the area of influence of the Dona Francisca hydroelectric power plant, South Brazil. Ambiente Sociedade 18, 19-34. doi: 10.1590/1809-4422ASOC825V18 42015

Rubino, E. C., and Doubleday, K. F. (2021). A gendered environmental justice perspective of tiger reintroductions to Sariska Tiger Reserve. J. Rural Soc. Sci. 36:5. Available online at: https://egrove.olemiss.edu/jrss/vol36/iss1/5

Sankar, K., Nigam, P., Malik, P. K., Qureshi, Q., and Bhattacharjee, S. (2013). Monitoring of Reintroduced Tigers (Panthera tigris tigris) in Sariska Tiger Reserve, Rajasthan. Dehradun: Wildlife Institute of India. doi: 10.1007/978-3-319-01345-9_7

Sansar Chand v. State of Rajasthan (2010). Criminal Appeal No. 2024/2009. Delhi: Supreme Court of India.

Sarkar, M. S., Ramesh, K., Johnson, J. A., Sen, S., Nigam, P., Gupta, S. K., et al. (2016). Movement and home range characteristics of reintroduced tiger (Panthera tigris) population in Panna Tiger Reserve, Central India. Eur. J. Wildl. Res. 62, 537-547. doi: 10.1007/s10344-016-1026-9

Sekhar, N. U. (1998). Crop and livestock depredation caused by wild animals in protected areas: the case of Sariska Tiger Reserve, Rajasthan, India. Environ. Conserv. 25, 160-171. doi: 10.1017/S03768929980 00204

Sekhar, N. U. (2003). Local people's attitudes towards conservation and wildlife tourism around Sariska Tiger Reserve, India. J. Environ. Manage. 69, 339-347. doi: 10.1016/j.jenvman.2003.09.002

Shahabuddin, G., Kumar, R., and Shrivastava, M. (2007). Creation of 'inviolate space': lives, livelihoods and conflict in Sariska Tiger Reserve. Econ. Polit. Wkly. 42, 1855-1862. doi: 10.2307/4419608

Shankar, M. (2007). “Taking stock of Sariska”. India Together. Available online at: http://www.indiatogether.org/sariska-environment-2 (accessed February 24, 2021).

Skogen, K., and Krange, O. (2003). A wolf at the gate: the anti-carnivore alliance and the symbolic construction of community. Sociologia ruralis, 43, 309-325. doi: $10.1111 / 1467-9523.00247$ 
Srivastava, M. (2010). “Tracking the tiger killers." India Today. Available online at: https://www.indiatoday.in/magazine/cover-story/story/20100607-trackingthe-tiger-killers-743050-2010-05-28 (accessed June 14, 2021)

Stahl, P., Vandel, J. M., Herrenschmidt, V., and Migot, P. (2001). Predation on livestock by an expanding reintroduced lynx population: long-term trend and spatial variability. J. Appl. Ecol. 38, 674-687. doi: 10.1046/j.1365-2664.2001.00625.x

Stoltzfus, J. C. (2011). Logistic regression: a brief primer. Acad. Emerg. Med. 18, 1099-1104. doi: 10.1111/j.1553-2712.2011.01185.x

Struebig, M. J., Linkie, M., Deere, N. J., Martyr, D. J., Millyanawati, B., Faulkner, S. C., et al. (2018). Addressing human-tiger conflict using socioecological information on tolerance and risk. Nat. Commun. 9, 3455. doi: $10.1038 / s 41467-018-05983-y$

Treves, A., and Bruskotter, J. (2014). Tolerance for predatory wildlife. Science 344, 476-477. doi: 10.1126/science. 1252690

Vasudeva, V., Ramasamy, P., Pal, R. S., Behera, G., Karat, P. R., and Krishnamurthy, R. (2021). Factors influencing people's response toward tiger translocation in Satkosia Tiger Reserve, Eastern India. Front. Conserv. Sci. 2, 664897. doi: $10.3389 /$ fcosc. 2021.664897

Wildlife Institute of India (2009). Status of Tiger and Its Prey Species in Panna Tiger Reserve, Madhya Pradesh. Final Report submitted to Madhya Pradesh Forest Department, Bhopal. Wildlife Institute of India, Dehradun, India.

WWF TAL Project (n.d.). The Terai Arc Landscape Project (TAL) Women's Groups. Available online at: https://www.wwfnepal.org//about_ wwf/where_we_work/tal/project/womens_groups/index.cfm (accessed July 12, 2019).
Zimmermann, A., Walpole, M. J., and Leader-Williams, N. (2005). Cattle ranchers' attitudes to conflicts with jaguar Panthera onca in the Pantanal of Brazil. Oryx 39, 406-412. doi: 10.1017/S00306053050 00992

Conflict of Interest: The authors declare that the research was conducted in the absence of any commercial or financial relationships that could be construed as a potential conflict of interest.

The reviewer $\mathrm{BB}$ declared a past collaboration with one of the authors RK to the handling editor.

Publisher's Note: All claims expressed in this article are solely those of the authors and do not necessarily represent those of their affiliated organizations, or those of the publisher, the editors and the reviewers. Any product that may be evaluated in this article, or claim that may be made by its manufacturer, is not guaranteed or endorsed by the publisher.

Copyright () 2022 Malviya, Kalyanasundaram and Krishnamurthy. This is an openaccess article distributed under the terms of the Creative Commons Attribution License (CC BY). The use, distribution or reproduction in other forums is permitted, provided the original author(s) and the copyright owner(s) are credited and that the original publication in this journal is cited, in accordance with accepted academic practice. No use, distribution or reproduction is permitted which does not comply with these terms. 